\title{
Intraduodenal Route of Administration
}

National Cancer Institute

\section{Source}

National Cancer Institute. Intraduodenal Route of Administration. NCI Thesaurus. Code C38241.

Administration of a drug within the duodenum. 